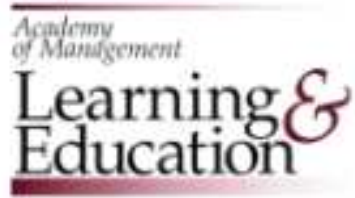

\title{
Self-Assessment of Knowledge: A cognitive learning or affective measure? \\ Perspectives from the management learning and education community
}

\begin{tabular}{|r|l|}
\hline Journal: & Learning \& Education \\
\hline Manuscript ID: & AMLE-ESS-2009-0159.R2 \\
\hline Manuscript Type: & Essays \\
\hline Submission Keywords: & Assessment of learning, Management learning \\
\hline & \\
\end{tabular}

5 ScholaroNE

Manuscript Central 
Self-Assessment of Knowledge: A cognitive learning or affective measure?

Perspectives from the management learning and education community

Steven J. Armstrong

Cynthia V. Fukami

Introduction

As the article, "Self-Assessment of Knowledge: A Cognitive Learning or Affective Measure?" indicates, scholars across many fields have grappled with how to best assess knowledge and learning. As a discipline, Management is no exception.

Recent decades have witnessed an unprecedented growth in management and executive development in the corporate world in order to maintain up-to-date knowledge and skills needed in today's highly competitive and dynamic environment (Armstrong \& Sadler-Smith, 2008). Ways of providing direct and systematic evidence of learning resulting from these time consuming and expensive workplace training programs, however, remain problematic. Recent decades have also witnessed increasing challenges for the way in which business schools provide evidence of student learning (Rubin \& Martell, 2009). Accrediting bodies such as AACSB and EQUIS are increasingly expecting critical evidence from direct, rather than indirect, measures of student learning as a way of ensuring that the goals that form the basis of the curriculum are being met (ibid). Both non-formal management development programs and formal management education programs would clearly benefit from quick and efficient ways of assessing knowledge. Self-report measures would seem an ideal way of determining the level of knowledge a person already has, or the increased levels of knowledge acquired as the result of a learning intervention. However, as Dunning et al (2004) remind us, more than 200 years have passed since Benjamin Franklin observed just how hard it is to know one's self. In their article that examines flawed self-assessment, they demonstrate that there still remains 'a striking continuity in the errors that people make when they assess themselves' (p98). Accurately self-assessing one's own performance seems notoriously difficult and peoples' self-perceptions appear to hold only a tenuous relationship with reality.

True, some previous studies have argued that student self-assessment can be as reliable as that of teachers (Stefani, 1994), that student ratings of instruction are a valid index of instructional effectiveness (Cohen, 1981), and 
that the benefits of self-assessment are so great that we should trust students to act appropriately (Cowan, 1988). Others, however, continue to express strong reservations about the usefulness of self-appraisal and assessment. In workplace settings, for example, accuracy of self-knowledge has been shown to be poor (Bass \& Yammarino, 1991; Campbell \& Lee, 1988; Zenger, 1992), and have only limited utility (Campbell, 1985: cited in Campbell \& Lee, 1988) except as a potential vehicle for personal development (Wexley \& Klimosy, 1984). In classroom settings the relationship between self-assessment and academic performance has been shown to range from very weak to moderate (Falchikov \& Boud, 1989; Hansford \& Hattie, 1982) with less competent individuals tending to inflate their self-assessments and highly competent individuals tending to under-assess (Kruger \& Dunning, 1999).

Despite this uncertainty, some researchers continue to interpret self-assessed knowledge as evidence of cognitive learning whereas others have become more interested in work that has demonstrated convincing correlations (moderate to large) between self-assessments of knowledge and affective, rather than cognitive, outcomes (Carswell, 2001 (cited in Sitzmann et al, 2010); Krawitz, 2004). Sitzmann, Ely, Brown \& Bauer (2010) have conducted an impressive meta-analytic study to shed light on these issues by comparing research evidence on the validity of self-assessments of knowledge across multiple disciplines. The study examines how closely selfassessments are related to affective and cognitive learning outcomes; whether course design or methodological factors influence the extent to which self-assessments correlate with cognitive learning; and how self-assessment of knowledge is used and interpreted in self-evaluation research. Data were included from 166 studies which reported 222 independent sample of data gathered from 41,237 learners comprising university students (75\%), employees $(21 \%)$ and military personnel (4\%).

The results reported in Sitzmann et al (2010) indicate that "self-assessments are best categorized as an affective evaluation outcome," rather than a cognitive evaluation outcome. Self-assessments of knowledge were strongly related to reactions and motivation, which suggests that they are useful as indicators of how learners feel about their learning experiences rather than as indicators of how much they learned. What is worrying is that this bias may lead to favorable self-assessment ratings when teaching is delivered in 'fun ways' but this will not necessarily lead to effective learning. The factors that produce a student's positive affective evaluation of a course are likely not the same factors that produce his or her learning. Simply put, we are not always happy while we are learning. The results of this study are reminiscent of the difference between assessing pay satisfaction and assuming 
it is the same as pay effectiveness (Lawler, 1971). It is one thing to be satisfied with one's pay; it is quite another to have the pay system work toward achieving your business strategy. Thus, a manager who is assessing the satisfaction of her direct reports with their pay would be making a mistake by equating their satisfaction levels with whether or not pay is linked to organizational effectiveness.

If self-assessments of learning are best categorized as capturing an affective outcome, and if effective learning is a result of a painful process, then it follows that effective learning may actually be negatively, rather than positively, related to self-assessments of learning. In addition, positive student evaluations of teaching may be similarly flawed as measures of affect rather than actual learning.

Support for the notion that learning involves pain can be found in various stage theories of adult development. In the seminal work, Childhood and Society, Erik Erikson (1950) posited that human beings progress through eight developmental stages. The movement between one stage to another is marked by conflict and tension surrounding a critical task. For development to occur, the conflict and tension must be understood and embraced so that a viable solution can be found. Thus, we can conclude that growth requires pain, the opposite of positive affect.

A similar idea is presented by Native Americans' teachings about the "Medicine Wheel." A Medicine Wheel is often an actual structure and is used in sacred rites (May \& Rodberg, 1996), including personal growth and development. In this context, the central essence of the medicine wheel is that each of us must make our own choices, but that others influence these choices, causing conflict and pain. As we move through life, we walk around the wheel seeking wisdom and new understanding. Once again, learning is thought to emerge from a painful process of self-discovery.

Overall, Sitzmann et al's (2010) study confirms that, when taken alone, self-assessments are not the single best way to measure learning. As the work cited above indicates, there is not a direct relationship between self- and other assessments. This is hardly surprising, since it is well known that any single measure of performance is inherently flawed by bias (March \& Sutton, 1998). For example, if we were to attempt to measure "teaching" performance with a single measure such as student evaluations, we will not be validly measuring teaching performance. A better approach is to take multiple viewpoints and multiple measures into account. So it follows that self-assessments on learning by themselves would be flawed as a measure of overall learning. 
This raises cause for concern, particularly considering the fact that despite sustained evidence to the contrary, $43 \%$ of studies over the past decade continued to interpret self-assessment data as evidence of learning. Even more disconcerting is that the level of disconnect between interpretation and reality varies across different disciplines and business and management experiences the second strongest level of disconnect of the six disciplines studied (communications, business, education, psychology, foreign language, medical education). More than $30 \%$ of studies in the field of business and management used self-assessed knowledge as a direct indicator of learning. This is despite the fact that $80 \%$ of studies in the literature that evaluated self-assessments in cognitive learning deemed them to be inaccurate.

Methods and Management Learning

So far, we have discussed construct-related issues of measuring knowledge and learning. We have concluded that learning is multidimensional, and thus, best assessed through multiple measures. We would be remiss if we didn't also mention that using single, self-reported measures of learning causes methodological concern. As an area of inquiry, the study of student learning in Management is at a relatively early stage of development (Schmidt-Wilk \& Fukami, 2009). The rigor of research is often connected with the age and stage of development of a discipline or paradigm. When a paradigm is well developed, there are higher expectations for rigor. For example, if a scholar were to submit a manuscript on the concept of job satisfaction to a journal for review today, it would not be acceptable to provide single measures of job satisfaction taken from self-reports. On the other hand, at early stages, quality criteria tend to be less stringent (Mahoney, 1985) and the discipline grants more slack in evaluating quality. A study in a new area with few precedents would therefore be allowed more methodological flaws or ambiguities than manuscripts within well-worked territories (Staw, 1985). Thus, given the relative newness of inquiry into Management learning, significant contributions have been made with less stringent methodological quality. There is some evidence, however, that a rise in methodological rigor in studies of Management learning is occurring.

Through the Journal of Management Education and its predecessors, Exchange and Organizational Behavior Teaching Review, there is a forty-year history of measuring learning in the field of Management. An analysis of the work published in these journals indicated that the methods of inquiry in Management education could be divided into three eras: early, middle, and emergent (Bilimoria \& Fukami, 2002). The Early era comprises 
the period between 1975 and 1984, when the journal was published under the title Exchange. Overall, the methods used in the earliest scholarship on teaching and learning in Management were rather simple and straightforward. The scholarship was largely based on evidence gathered from one sample and one perspective. There was much rich qualitative information, but the presentation most closely resembled a case study methodology - scholars collected information themselves about their own teaching practices, and there was typically only one perspective represented, that of the scholar himself or herself. Finally, the data were rarely, if ever, analyzed with statistical procedures.

The "middle" era corresponded to the years 1984-1991, when the journal was published under the title Organizational Behavior Teaching Review. About half of the articles from this stage included some attempt by the authors, either through qualitative or quantitative methods, to provide stronger evidence to support the articles' conclusions. The third, or "emergent" era began in 1991, when the journal began publication under the title Journal of Management Education, its current title. In this era, more than half of the articles reported data with statistical analyses, including hypothesis testing. Thus, the bar had been raised regarding the standards of evidence.

Overall, when viewed across the three eras, the methods used in the scholarship of teaching and learning in Management have clearly evolved and matured. The work is more cumulative, and presented with more statistical rigor. Multiple measures from multiple viewpoints are included in the evidence provided. It is our view that the conclusions in the article, "Self-Assessment of Knowledge: A Cognitive Learning or Affective Measure?" are consistent with the idea that measurement within the scholarship of teaching and learning has rightly become more rigorous. Using self-assessments of learning provides one voice. Valid assessments of learning require triangulation from data gleaned from multiple voices.

Conclusions and Implications for Management Learning and Education

In the context of management, and in light of what we know from the study conducted by Sitzmann et al (2010), it may be time to move to a new stage of development. One way forward is to take stock of what has gone on before and ask ourselves precisely what is it that we should be assessing, why is this important, and how should we do it? In order to begin to address these questions it may be helpful to explore the relationship between learning and assessment in a little more detail.

In order to choose appropriate assessment methods we must first of all specify the knowledge, skills or behaviors associated with learning goals and objectives. A useful classification scheme based on more than 50 years 
of learning theory is put forward by Rubin and Martell (2009) to help with this. Outlined in Table 1, the scheme relies on first identifying the learning outcome category - broadly defined as (1) cognitive, (2) skill or (3) affective.

(1) Cognitive learning outcomes refer to the acquisition of knowledge that can be categorized into the three domains of: declarative knowledge (amount and accuracy of knowledge acquired); knowledge organization (understanding of interrelationships between knowledge structures); and cognitive strategies (forming concepts and procedures).

(2) Skill-based learning outcomes involve demonstrating technical or motor skills that learners have not previously held as well as the capacity to perform these skills with fluidity under real conditions (Kraiger, 2002).

(3) Affective learning outcomes refer to learners' attitudes or motivations toward the particular learning objective, including learners' convictions and confidence levels, also referred to as self-efficacy. These outcomes are also referred to as reaction measures.

Because affective criteria exist solely within the person, measuring affective outcomes is most typically done using self-report instruments (Rubin \& Martell, 2009) and the results of Sitzmann et al.'s (2010) study should therefore come as no surprise. Measuring affective outcomes in management education, however, is discouraged by accrediting bodies such as AACSB in favor of skill and cognitive outcomes and this is perhaps for very good reasons.

Returning to our earlier question of what it is that we should be assessing in the context of management education, and why, there are strong arguments suggesting that most learning to manage occurs on the job (Dawes et al., 1996) in tacit, culturally embedded ways through peoples work practices within organizations. Knowledge that is tacit (or procedural) in nature has been argued to be critically important for successful managers (Argyris, 1999) in terms of both managerial performance and success (Sternberg et al., 2000) and ways in which expert managers are distinguished from others (Armstrong \& Mahmud, 2008; Wagner \& Sternberg, 1987). Tacit knowledge, a product of learning from experience, is about how to do something whereas declarative knowledge is more about something (Anderson, 1983). Declarative knowledge is consciously formed, controlled and articulatable, while tacit knowledge is identified as unconscious with automatic learning, which guides actions and decisions without being in our field of consciousness. It follows, therefore, that if tacit knowledge is the stuff of managers, then it is tacit knowledge and skill compilation that should be at the heart of our assessment procedures. Yet few institutions focus their 
assessment efforts on these sorts of outcomes (Bommer, Rubin \& Bartels, 2005) and declarative knowledge continues to be the traditional focus of university based assessment (Rubin \& Martell, 2009). But before we can consider ways of assessing the knowledge and skills associated with successful managers we must first of all find ways of more effectively facilitating their acquisition. As Armstrong (2005) notes "because full-time formal education separates learning from practice, it is inevitable that the educational process will produce people who can talk about practice rather than people who are competent practitioners" (p230). Despite calls for different teaching approaches spanning more than 30 years (Argyris \& Schön, 1974), management graduates continue to be criticized for displaying analytical detachment to the detriment of insight (Hayes \& Albernathy, 1980) and for having the impression that management problems can be perceived as neat technical packages (Raelin, 1985) leading some authors to assert that management education is still in a parlous state (Grey, 2004). To address these problems, some have argued for more innovative approaches to teaching and learning that require a radical shift from tutor driven teaching to near total participation and engagement of the learner (Armstrong \& Fukami, 2009). These issues represent a fertile area for future research investigations.

Finally, there may be some good news in the results of the study by Sitzmann and her colleagues. Learning is clearly a multidimensional construct, and requires more rigorous research. This also indicates to us that various aspects of the educational process may affect cognitive learning while other aspects are more strongly related to affective outcomes. More awareness of what factors influence what dependent variable will help educators to better design effective learning systems. In addition, Sitzmann et al (2010) did find that the relationship between self assessments and cognitive learning is strongest when learners are not only given the opportunity to self-assess but also receive external feedback both on the accuracy of their self-assessments and on their overall learning performance. This suggests that self-assessment might actually be a valuable skill. In order to develop learners' selfassessment skills more effectively, learning providers need to provide them not only with feedback about their performance to help them calibrate their self-assessments of knowledge, but also enable them to practice selfassessments of knowledge and provide them with regular feedback on the accuracy of their endeavors. Interestingly, the relationship between self-assessments and cognitive learning (presumably resulting in declarative rather than tacit knowledge) was also found to be stronger when learners were asked to report their current knowledge level rather than knowledge gain. This is presumably because absolute self-assessments of knowledge are better matched with cognitive learning than self-assessment of their knowledge gain. 
1

2

3

4

5

6

7

8

9

10

11

12

13

14

15

16

17

18

19

20

21

22

23

24

25

26

27

28

29

30

31

32

33

34

35

36

37

38

39

40

41

42

43

44

45

46

47

48

49

50

51

52

53

54

55

56

57

58

59

60
While we might have expected that self-assessments of learning were suspect, it is gratifying to be presented with solid evidence of the same. The time has clearly come for more complex measures of learning, arguably the most important dependent variable in Management Learning, Education, and Development. 


\section{Table 1 Classification of assessment learning outcomes}

\begin{tabular}{|c|c|c|c|}
\hline Learning Outcome Category & Learning Concept & Measurement Focus & Potential Assessment Methods \\
\hline \multirow[t]{3}{*}{ Cognitive Outcomes } & Verbal (declarative) knowledge & $\begin{array}{l}\text { Quantity of knowledge, recall } \\
\text { accuracy, speed of recall }\end{array}$ & $\begin{array}{l}\text { Exams testing recognition (e.g. } \\
\text { multiple choice) or recall (e.g. essay, } \\
\text { fill-in-the blank) }\end{array}$ \\
\hline & Knowledge organization & $\begin{array}{l}\text { Idea similarity, knowledge } \\
\text { interrelatedness, hierarchical ordering }\end{array}$ & Concept mapping or card sorting \\
\hline & Cognitive strategies & $\begin{array}{l}\text { Forming concepts and procedures, } \\
\text { problem solving }\end{array}$ & Case scenarios, problem sets \\
\hline \multirow[t]{2}{*}{ Skill Outcomes } & Skill acquisition & Proceduralization compilation & $\begin{array}{l}\text { Assessment centres, work samples, } \\
\text { role plays, behavioural checklists, } \\
\text { presentations }\end{array}$ \\
\hline & Automaticity & Automatic processing & $\begin{array}{l}\text { Behavioral observation, performance } \\
\text { ratings }\end{array}$ \\
\hline \multirow[t]{2}{*}{ Affective Outcomes } & Attitude & $\begin{array}{l}\text { Target object (e.g. ethics), attitude } \\
\text { strength, self efficacy }\end{array}$ & Self-report, task specific self-efficacy \\
\hline & Motivation & $\begin{array}{l}\text { Effort, Tenacity, Goal difficulty, } \\
\text { motivation to learn }\end{array}$ & $\begin{array}{l}\text { Self-report, observation, time-on-task, } \\
\text { goal-difficulty ratings }\end{array}$ \\
\hline
\end{tabular}

Source: Rubin \& Martell (2009) (originally adapted from Kraiger (2003) and Kraiger et al. (1993)) 
Anderson, J. (1983). The architecture of cognition. Cambridge, MA: Harvard University Press.

Armstrong, S.J. (2005). Postgraduate management education in the UK: Lessons from or lessons for the US model? Academy of Management Learning and Education, Vol 4, No 2, 229-234.

Armstrong, S.J. (2007) Re-thinking Management Education: From cognition, to action, to learning. Research Memorandum (75), The Business School, University of Hull, Hull, UK.

Armstrong, S.J. \& Fukami, C.V. (2009). Past, present and future perspectives of management learning, education and development. In S.J. Armstrong \& C.V. Fukami (Eds). The Sage Handbook of Management Learning, Education and Development. London: Sage.

Armstrong, S.J. \& Mahmud, A. (2008). Experiential Learning and the Acquisition of Managerial Tacit Knowledge. Academy of Management Learning and Education, Vol 7, No 2, 189-208.

Armstrong, S.J. \& Sadler-Smith, E. (2008). Learning on Demand, at Your Own Pace, in Rapid Bite-Sized-Chunks: The Future Shape of Management Development? Academy of Management Learning \& Education, Vol 7, No 4, 571-586.

Argyris, C. (1999). Tacit Knowledge and Management. In R. J. Sternberg \& J. A. Horvath (Eds.), Tacit knowledge in professional practice: researcher and practitioner perspectives. Mahwah, N.J.: L. Erlbaum.

Bass, B.M. \& Yammarino, F.J. (1991). Congruence of self and others' leadership ratings of Naval officers for understanding successful performance. Applied Psychology, 40, 437-454.

Bilimoria, D. \& Fukami, C. (2002). The scholarship of teaching and learning in the Management sciences: Disciplinary style and content. In M. T. Huber \& S. P. Morreale (Eds.), Disciplinary Styles in the Scholarship of Teaching and Learning: Exploring Common Ground (pp. 125-142). Menlo Park, CA: The Carnegie Foundation for the Advancement of Teaching and the American Association for Higher Education.

Bommer, W.H., Rubin, R.S. \& Bartels, L.K. (2005). Assessing the unassessable: Interpersonal and managerial skills, in K. Martel \& T. Calderon (eds.), Assessment of student learning in business schools: Best practices each step of the way (pp. 103-129). Tallahassee,FL: Association for Institutional Research.

Campbell, D.J. (1985). Self-appraisals from two perspectives: Esteem versus consistency influences. Proceedings of the Mid-West Academy of Management, 110-114.

Campbell, D. J., \& Lee, C. (1988). Self-appraisal in performance evaluation: Development versus evaluation. Academy of Management Review, 13, 302-314.

Carswell, A.D. (2001). Facilitating student learning in an asynchronous learning network. Unpublished doctoral dissertation, University of Maryland, College Park.

Cohen, P. A. (1981). Student ratings of instruction and student achievement: A meta-analysis of multisection validity studies. Review of Educational Research, 51, 281-309

Cowan, J. (1988). Struggling with student self assessment, in D.J.Boud (Ed.), Developing student autonomy in learning, $2^{\text {nd }}$ edn, 192-210. London: Kogan Page.

Dawes, G., Bennett, B., Cunningham, C. \& Cunningham, I. (1996). Learning and Development in Organisations. St. Albans: Strategic Developments. 
Dunning, D., Heath, C., \& Suls, J. M. (2004). Flawed self-assessment: Implications for health, education, and the workplace. Psychological Science in the Public Interest, 5(3), 69-106.

Erik E. (1950). Childhood and society. New York: Norton.

Falchikov, N., \& Boud, D. (1989). Student self-assessment in higher education: A meta-analysis. Review of Educational Research, 59, 395-430.

Forsythe, G., Hedlund, J. Snook, S., Horvath, J., Williams, W., Bullis, R., Dennis, M., \& Sternberg, R. (1998). Construct Validation of Tacit Knowledge for Military Leadership. Paper presented at the Annual Meeting of the American Educational Research Association, San Diego, California, April 13-17, 1998. Available: http://www.aera.net/divisions/i/home/ForsythePaper.pdf

Hansford, B.C. \& Hattie, J.A. (1982). The relationship between self and achievement/performance measures. Review of Educational Research, 52, 123-142.

Hayes, R.H., \& Albernathy, W. (1980). Managing our way to economic decline. Harvard Business Review, 59: 6777.

Kraiger, K., Ford, J. K., \& Salas, E. (1993). Application of cognitive, skill-based, and affective theories of learning outcomes to new methods of training evaluation. Journal of Applied Psychology, 78, 311-328.

Kraiger, K. (2002). Decision based evaluation, in K. Kraiger (ed.), Creating, implementing, and managing effective training and development: State-of-the-art lessons for practice, 331-376. San Francisco, CA: Jossey-Bass.

Krawitz, R. (2004). Borderline personality disorder: Attitudinal change following training. Australian and New Zealand Journal of Psychiatry, 38, 554-559.

Kruger, J., \& Dunning, D. (1999). Unskilled and unaware of it: How difficulties in recognizing one's own incompetence lead to inflated self-assessments. Journal of Personality and Social Psychology, 77, 11211134.

Lawler, E. E. (1971). Pay and Organizational Effectiveness: A Psychological View. New York: McGraw- Hill.

Mahoney, T.A. (1985). Journal publishing in the Organization Sciences: An analysis of exchanges. In L.L. Cummings \& P. J. Frost. (Eds.) Publishing in the Organizational Sciences. (pp. 14-34). Homewood, IL: Irwin.

March, J. \& Sutton, R. (1998). Organizational Performance as a Dependent Variable. Organization Science 8, 698710 .

May, V. \& Rodberg, C.V. (1996). Medicine Wheel Ceremonies: Ancient Philosophies for Use in Modern Day Life, Happy Camp, CA: Naturegraph Publishers.

Rubin, R.S. \& Martell, K. (2009). Assessment and Accreditation in Business Schools. In S.J. Armstrong \& C.V. Fukami (Eds.), The Sage Handbook of Management Learning, Education and Development. London: Sage.

Schmidt-Wilk, Jane and Cynthia Fukami (2009). Relevance With Rigor: Stories From The Journal of Management Education. In Charles Wankel and Robert DeFillippi (eds.) Being and Becoming a Management Education Scholar (Charlotte, NC: Information Age Publishing).

Sitzmann, T., Ely, K., Brown, K. \& Bauer, K. (2010). Self assessment of knowledge: A cognitive learning or affective measure? Academy of Management Learning and Education, Vol 9, No 2. 
Staw, Barry M. (1985). Repairs on the road to relevance and rigor. In L.L. Cummings \& P.J. Frost (Eds.), Publishing in the Organizational Sciences. (pp. 96-107) Homewood, IL: Richard D. Irwin.

Stefani, L.A.J. (1994). Peer, self and tutor assessment: Relative reliabilities. Studies in Higher Education, Vol 19, No 1, 69-75.

Sternberg, R., Forsythe, G., Hedlund, J., Horvath, J., Wagner, R., Williams, W., Snook, S., \& Grigorenko, E. (2000). Practical intelligence in everyday life. New York: Cambridge University Press.

Wagner, R. K. \& Sternberg, R. J. (1987). Tacit knowledge in managerial success. Journal of Business and Psychology, 1, 4, 301-312.

Wagner, R. K. \& Sternberg, R. J. (1985). Practical intelligence in real-world pursuits: The role of tacit knowledge. Journal of Personality and Social Psychology, 48, 436-458.

Wexley, K.N. \& Klimoski, R. (1984). Performance appraisal: An update. In K.M. Rowland \& G.D. Ferris (Eds.), Research in personnel \& human resource management, Vol 2, 35-79. Greenwich, CT: JAI Press.

Zenger, T.R. (1992). Why do employers only reward extreme performance? Examining the relationships among performance, pay, and turnover. Administrative Science Quarterly, 37, 198-219. 